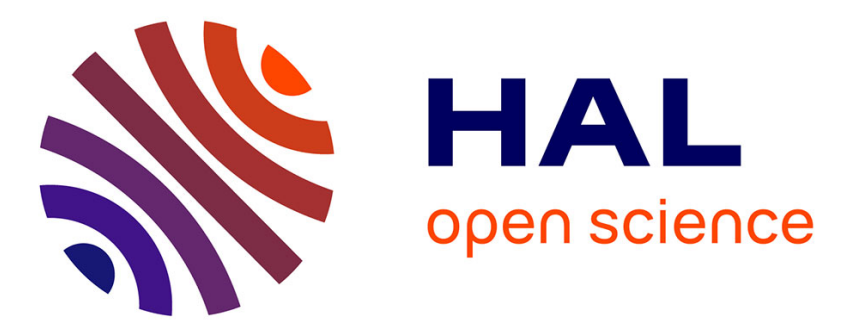

\title{
Is Crohn's creeping fat an adipose tissue?
}

Isabelle Olivier, Vassilia Theodorou, Philippe Valet, Isabelle Castan-Laurell, Hervé Guillou, Justine Bertrand-Michel, Christel Cartier, Valérie Bézirard, Robert Ducroc, Jean-Pierre Segain, et al.

\section{- To cite this version:}

Isabelle Olivier, Vassilia Theodorou, Philippe Valet, Isabelle Castan-Laurell, Hervé Guillou, et al.. Is Crohn's creeping fat an adipose tissue?. Inflammatory Bowel Diseases, 2011, 17 (3), pp.747-57. 10.1002/ibd.21413 . inserm-00617823

\section{HAL Id: inserm-00617823 https://www.hal.inserm.fr/inserm-00617823}

Submitted on 29 May 2020

HAL is a multi-disciplinary open access archive for the deposit and dissemination of scientific research documents, whether they are published or not. The documents may come from teaching and research institutions in France or abroad, or from public or private research centers.
L'archive ouverte pluridisciplinaire HAL, est destinée au dépôt et à la diffusion de documents scientifiques de niveau recherche, publiés ou non, émanant des établissements d'enseignement et de recherche français ou étrangers, des laboratoires publics ou privés. 


\title{
Is Crohn's Creeping Fat an Adipose Tissue?
}

\author{
Isabelle Olivier, MSc, ${ }^{*}$ Vassilia Théodorou, $P h D_{1}^{+}$Philippe Valet, $P h D_{,}^{\neq}$Isabelle Castan-Laurell, PhD, ${ }^{\neq}$ \\ Hervé Guillou, PhD, ${ }^{\S}$ Justine Bertrand-Michel, PhD," Christel Cartier, MSc, * Valérie Bezirard, MSc, * \\ Robert Ducroc, PhD, Jean-Pierre Segain, PhD, ${ }^{* *}$ Guillaume Portier, $M D_{1}^{++}$Sylvain Kirzin, $M D_{1}{ }^{+t}$ \\ Jacques Moreau, $M D^{, \neq}$Jean-Pierre Duffas, $M D_{1}{ }^{\neq \neq}$Laurent Ferrier, $P h D^{*}$ and Hélène Eutamène, $P h D^{+}$
}

\begin{abstract}
Background: In human pathology, the "creeping fat" (CF) of the mesentery is unique to Crohn's disease (CD). CF is usually referred to as an ectopic extension of mesenteric adipose tissue (MAT). However, since no animal model developing CF has ever been established, very little is known about this type of fat-depot expansion and its role in the development of the disease.
\end{abstract}

Methods: We developed and standardized an experimental protocol in mice that reproducibly induces $\mathrm{CF}$ development when a severe colonic inflammation is obtained by intracolonic instillation of DNBS.

Results: Macro-microscopic observations revealed a fatty appearance of CF. Yet when compared to MAT from the same animals, CF contains very little triglycerides, few adipocytes, and we observed a very low expression and protein levels of both adipose markers (hormone-sensitive lipase, perilipin) and adipocytokines (leptin, adiponectin). The decreased expression of perilipin in CF was also observed by immunohistochemistry. Conversely, the expression of proinflammatory and fibrous markers (Pref-1) was much higher in $\mathrm{CF}$ than in MAT. These observations were fully consistent with those made on $\mathrm{CF}$ recovered from five $\mathrm{CD}$ patients and compared with subcutaneous and mesenteric fat from the same patients.

Received for publication June 4, 2010; Accepted June 7, 2010.

From the *INRA, UMR 1054, Neuro-Gastroenterology \& Nutrition Unit, Toulouse, France, 'University of Toulouse, EI-Purpan, UMR 1054, NeuroGastroenterology \& Nutrition Unit, Toulouse, France, ${ }^{+}$INSERM, I2MR, Adipocyte secretions, Obesities and Associated Pathologies team, Toulouse, France, ${ }^{8}$ INRA, UR66, Pharmacology Toxicology Unit, Toulouse, France, "IFR150, INSERM U563, Toulouse, France, "INSERM U773, Center of Biomedical Research Bichat-Beaujon, CRB3, Paris, France, ${ }^{* *}$ INRA, UMR 1280, Physiology of Nutritional Adaptations, Nantes, France, ${ }^{\dagger \dagger}$ Department of Digestive Surgery, Purpan University Hospital, Toulouse, France, ${ }^{\$}$ Department of Digestive Surgery, Rangueil University Hospital, Toulouse, France.

The last two authors contributed equally.

Reprints: Vassilia Théodorou, PhD, INRA, EI-Purpan, UMR1054, Neuro-Gastroenterology and Nutrition Unit, 180 chemin de Tournefeuille, BP 93173, 31027 Toulouse Cedex 3, France (e-mail: vtheodor@toulouse. inra.fr)

Supported by an institutional grant from the INRA. Isabelle Olivier is the recipient of joint fellowship from INRA and région Midi-Pyrénées.

Copyright (c) 2010 Crohn's \& Colitis Foundation of America, Inc.

DOI 10.1002/ibd.21413

Published online 3 August 2010 in Wiley OnlineLibrary (wileyonlinelibrary.com).
Conclusions: Altogether, this work reports an original experimental mice model of CF. In this model we establish for the first time that $\mathrm{CF}$ only occurs in severe colonic inflammation and shows an inflammatory, fibrous but not an adipose pattern.

(Inflamm Bowel Dis 2011;17:747-757)

Key Words: creeping fat, mesenteric adipose tissue, Crohn's disease, animal model

U lcerative colitis and Crohn's disease (CD) are the most common forms of inflammatory bowel disease (IBD). The hallmarks of $\mathrm{CD}$ are chronicity and uncontrolled inflammation of intestinal mucosa which can affect any part of the gastrointestinal tract, but most commonly occurring in the distal ileum and/or colon. At the onset of disease, although patients show a weight loss, ${ }^{1}$ a specific hypertrophy of mesenteric adipose tissue (MAT) has been evidenced. ${ }^{2}$ In addition, an ectopic tissue surrounding the inflammatory and ulcerated areas has also been identified by Crohn et $\mathrm{al}^{3}$ in the first original description of the disease in 1932. This ectopic tissue is referred to as "creeping fat" $(\mathrm{CF})$. In the literature, $\mathrm{CF}$ is described as a proliferation and an extension of the mesenteric adipose tissue. $\mathrm{CF}$ is encroached at the antimesenteric surface of the bowel and surgical description defined $\mathrm{CF}$ as more than $50 \%$ coverage of the intestinal surface. ${ }^{4}$ Moreover, surgeons are familiar with $\mathrm{CF}$ and use it as an anatomical marker to delineate the extent of active disease. ${ }^{5} \mathrm{CF}$ is present in all $\mathrm{CD}$ patients undergoing ileal resection and correlates with the degree of inflammation. ${ }^{6}$ Although this $\mathrm{CF}$ is known since $\mathrm{CD}$ was first described, the pathophysiological relevance of this ectopic tissue remains unknown since most human studies do not distinguish between MAT and CF.

White adipose tissue (WAT) was first described as a passive tissue that stores energy as triglycerides (TG) after food intake and releases energy as free fatty acid during the fasting state. During the past 10 years this point of view has totally changed and the adipose tissue is described as a real endocrine organ. A wide variety of products such as adipocytokines, chemokines, leptin, and adiponectin are expressed and secreted by the adipose tissue. The description of MAT and CF make it interesting 
by its hypertrophy and its capacity to secrete pro- and antiinflammatory products. These tissues have been studied in recent years and the pathophysiological roles of their secretions (e.g., leptin, adiponectin) remain under debate..$^{7,8}$

So far, no description of CF morphology, metabolism, and/or function is established in the literature. This lack of knowledge is due to the absence of an appropriate animal model allowing CF development, despite several animal models of chronic intestinal inflammation being extensively used, e.g., dextran sulfate sodium (DSS), trinitro benzene sulfonic acid (TNBS) or dinitrobenzene sulfonic acid (DNBS). ${ }^{9}$ The intrarectal (IR) administration of DNBS hapten reagent in ethanol solution causes disruption of the epithelial layer and exposes lamina propria to bacterial and host-haptened protein. The intestinal inflammation induced by DNBS has many characteristic features of CD in humans, including severe transmural inflammation associated with diarrhea, rectal prolapse, and weight loss. In spite of the common use of this animal model of colitis, development of CF was never described. Thus, the aim of the present study was, on the one hand, to define the conditions of colonic inflammation by IR administration of DNBS to set up a mice model of colitis allowing the development of CF. On the other hand, we describe MAT and characterize the $\mathrm{CF}$ obtained in these specific colonic inflammatory conditions. Finally, we validated the relevance of our model using human tissues.

\section{MATERIALS AND METHODS}

\section{Animals}

Nine-week-old male Balb/c mice, weighing $23 \pm 0.5$ g (Charles River Laboratories, L'Arbresle, France) were used in this study. Mice had free access to water and food and were maintained in the pathogen-free animal facility at a constant temperature $\left(23 \pm 1^{\circ} \mathrm{C}\right)$ on a $12 / 12$ hour light/ dark cycle.

\section{Human Samples}

Five patients (35-45 years old) suffering from CD were included in this study. All patients provided written and informed consent to participate in this study. Tissues samples of CF, MAT, and subcutaneous adipose tissue were collected at both CHU Purpan and CHU Rangueil, Toulouse, France during ileocecal resection.

\section{Induction of Colitis by DNBS}

Colitis was induced by IR administration of DNBS (Fluka, Saint Quentin-Fallavier, France). A stock solution of DNBS was prepared by dissolving $65 \mathrm{mg}$ of DNBS in 1 $\mathrm{mL}$ of $50 \%$ ethanol, $50 \%$ saline solution. Mice were anesthetized with ketamine $(100 \mathrm{mg} / \mathrm{kg})$ and xylazine $(10 \mathrm{mg} /$ $\mathrm{kg}$ ), instilled in the colon at $4 \mathrm{~cm}$ from the anus, using a polyethylene catheter, with $100 \mu \mathrm{L}$ of this solution. After the instillation, the mice were held upside down by their tails for 15 seconds and received $0.2 \mathrm{~mL}$ of saline (subcutaneously, s.c.) to prevent dehydration. Control mice were anesthetized and perfused with $100 \mu \mathrm{L}$ of saline. The mice were sacrificed 3 days after the induction of colitis.

\section{Mice Body Weight and Colon Length}

The weight of mice was recorded the day of instillation and the day of sacrifice. The colon length was measured after the sacrifice.

\section{Adipose Depot Dissection}

Three days after DNBS instillation mice were sacrificed by exsanguination. Perigonadic adipose tissue, MAT, $\mathrm{CF}$, and colon were dissected. MAT was defined as the adipose tissue surrounding the lymph nodes and around the cecum. CF identified as a tissue surrounding the ulcerative colonic area was gently removed. The samples were directly frozen at $-80^{\circ} \mathrm{C}$.

\section{Macroscopic Damage Scores}

Immediately after sacrifice the colon was removed and rinsed with saline. Intestinal damage was scored according to a modified scale of Wallace et al. ${ }^{10}$ Briefly, the presence of mucosal hyperemia and bowel wall thickening, the severity and extent of ulceration and necrosis, the tissue adhesion, and the occurrence of diarrhea were rated according to a macroscopic damage score (MDS) ranging from 0 (normal appearance) to 10 (severe lesions).

\section{Myeloperoxidase Activity}

The measurement of myeloperoxidase (MPO) activity, a marker of polymorphonuclear primary granules, was measured in the colon and in adipose tissue (MAT and $\mathrm{CF}$ ), as described previously. The totality of tissue (colon or adipose tissue) was suspended in potassium phosphate buffer $\left(\mathrm{KH}_{2} \mathrm{PO}_{4} 44 \mathrm{mM}, \mathrm{K}_{2} \mathrm{HPO}_{4} 6 \mathrm{mM}\right.$, pH 6.0), homogenized on ice with Polytron (PCU-2, Kinematica, Lucerne, Switzerland) and submitted to three cycles of freezing and thawing. Homogenates were then centrifuged at 10,000 rpm for 15 minutes at $4{ }^{\circ} \mathrm{C}$. The pellets were resuspended in hexadecyl trimethylammonium bromide buffer $(0.5 \%$; $\mathrm{wt} / \mathrm{vol}$; in potassium phosphate buffer) to release MPO from polymorphonuclear neutrophil primary granules. These suspensions were sonicated (Büchi, Flawil, Switzerland) on ice and centrifuged at 10,000 rpm for 15 minutes at $4^{\circ} \mathrm{C}$. Supernatant fractions were diluted in potassium phosphate buffer containing $0.167 \mathrm{mg}$ O-dianisidine dihydrochloride $/ \mathrm{mL}$ and $0.00005 \%$ (vol $/ \mathrm{vol}$ ) $\mathrm{H}_{2} \mathrm{O}_{2}$. MPO from human neutrophils (Sigma, Saint Quentin Fallavier, France; $0.1 \mathrm{U} / \mathrm{mL}$ ) was used as a standard. Changes in absorbance at $450 \mathrm{~nm}$ were recorded with a spectrophotometer every 
10 seconds over 2 minutes. One unit of MPO activity was defined as the quantity of MPO degrading $1 \mu$ mol $\mathrm{H}_{2} \mathrm{O}_{2}$ $\mathrm{min}^{-1} \mathrm{~mL}^{-1}$ at $25^{\circ} \mathrm{C}$. Protein concentrations $(\mathrm{mg} / \mathrm{mL})$ were determined using a modified method of Lowry (Detergent Compatible Assay, BioRad, Ivry/Seine, France) and MPO activity was expressed as MPO units/g protein.

\section{Plasmatic Assays}

Plasma from control animals and mice with MDS $>4$ were collected. Samples were then processed for enzymelinked immunosorbent assay (ELISA) using commercial kits to determine plasma levels of IL-6 and adiponectin (Invitrogen, Cergy-Pontoise, France) according to the manufacturers' protocols, and data are expressed as concentration per $\mathrm{mL}$ (IL-6) or $\mu \mathrm{L}$ (adiponectin) of plasma.

\section{Histological Studies}

The collected samples were fixed in formaldehyde $40 \%$ for 24 hours, embedded in paraffin blocks, and cut into $5 \mu \mathrm{m}$ sections for histology analysis. Paraffin sections were stained with hemalun and eosin $(\mathrm{H} \& \mathrm{E})$.

\section{Immunohistochemistry}

Colonic samples were fixed for 12 hours in $4 \%$ formalin, dehydrated through graded ethanol, and embedded in paraffin. Sections $(5 \mu \mathrm{m})$ were rehydrated and submerged in antigen retrieval solution (citrate buffer, $10 \mathrm{mM}$, $\mathrm{pH} 6,95^{\circ} \mathrm{C}, 10$ minutes). After inhibition of endogenous peroxidases with $3 \% \mathrm{H}_{2} \mathrm{O}_{2}$ in Tris-buffered saline solution containing $0.1 \%$ Tween20 (TBST) for 10 minutes and incubation in blocking solution (TBST with 5\% goat normal serum), sections were incubated with rabbit perilipin primary antibody (Ozyme, Saint-Quentin Yvelines, France) (1/100, overnight, $\left.4^{\circ} \mathrm{C}\right)$ followed by a biotinylated goat antirabbit $\mathrm{IgG}$ immune serum (30 minutes, room temperature) and subsequently with $\mathrm{ABC}$ complexes coupled to peroxidase (Vectastain Elite ABC kit, AbCys, Paris, France). Antigen-antibody complexes were revealed using 3-3' diaminobenzidine (DAB kit, Clinisciences, Montrouge, France) and sections were dehydrated and mounted. As negative controls, sections were treated with the same procedure except for the presence of primary antibody.

\section{Digestion by Collagenase}

MAT and CF were digested in Dulbecco's modified Eagle's medium (DMEM) medium containing $1 \mathrm{mg} / \mathrm{mL}$ collagenase (Sigma-Aldrich) and 1\% BSA (Euromedex) for 30-45 minutes at $37^{\circ} \mathrm{C}$ under shaking. The floating adipocytes were separated from the medium containing the stroma-vascular fraction (SVF).

\section{Oil Red O Staining}

Frozen sections of MAT and CF were fixed in icecold $10 \%$ formalin. The sections were briefly incubated in propan-2-ol solution and in oil red $\mathrm{O}$ solution $(0.2 \mathrm{~g}$ in 100 $\mathrm{mL}$ of propan-2-ol) for 20 minutes. The sections were rinsed with distilled water. Lipids were stained in red.

\section{Lipid Profiling}

TGs and fatty acids assay were performed as previously described. ${ }^{11,12}$ Briefly, following homogenization of tissue samples in methanol / 5 mM EGTA (2:1 v/v), lipids corresponding to an equivalent of $1 \mathrm{mg}$ of tissue were extracted according to Bligh and Dyer ${ }^{12}$ in chloroform/ methanol/water $(2.5: 2.5: 2.1, \mathrm{v} / \mathrm{v} / \mathrm{v})$ in the presence of the internal standard: glyceryl triheptadecanoate. TGs were analyzed by gas-liquid chromatography on a FOCUS Thermo Electron system using a Zebron-1 Phenomenex fused silica capillary columns $(5 \mathrm{~m} \times 0.32 \mathrm{~mm}$ i.d., $0.50 \mathrm{~mm}$ film thickness). The oven temperature was programmed from $200-350^{\circ} \mathrm{C}$ at a rate of $5^{\circ} \mathrm{C}$ per minute and the carrier gas was hydrogen $(0.5 \mathrm{bar})$. The injector and the detector were at $315^{\circ} \mathrm{C}$ and $345^{\circ} \mathrm{C}$, respectively.

To measure total fatty acid methyl ester molecular species (FAME), lipids corresponding to an equivalent of 1 $\mathrm{mg}$ of tissue were extracted in the presence of glyceryl triheptadecanoate $(0.5 \mu \mathrm{g})$ as an internal standard. The lipid extract was transmethylated with $2 \mathrm{~mL}$ of BF3 in methanol/hexane $(1: 1)$ for 60 minutes at $100^{\circ} \mathrm{C}$ and the FAMEs were then extracted after addition of $2 \mathrm{~mL}$ of hexane and 1 $\mathrm{mL}$ of water. The organic phase was evaporated to dryness and dissolved in $50 \mu \mathrm{L}$ ethyl acetate. One $\mu \mathrm{L}$ of FAME was analyzed by gas-liquid chromatography on a 5890 Hewlett Packard system using a Famewax RESTEK fused silica capillary columns $(30 \mathrm{~m} \times 0.32 \mathrm{~mm}$ i.d., $0.25 \mathrm{~mm}$ film thickness). The oven temperature was programmed from $110-220^{\circ} \mathrm{C}$ at a rate of $2^{\circ} \mathrm{C}$ per minute and the carrier gas was hydrogen $(0.5$ bar $)$. The injector and the detector were at $225^{\circ} \mathrm{C}$ and $245^{\circ} \mathrm{C}$, respectively.

\section{mRNA Expression by Real-time Reverse- transcription Polymerase Chain Reaction (RT-PCR)}

Total RNAs were extracted using the RNeasy mini kit (Qiagen, Courtaboeuf, France) and 500 ng were reverse-transcribed for 60 minutes at $37^{\circ} \mathrm{C}$ using Superscript II reverse transcriptase (Invitrogen) in the presence of random hexamers. A minus reverse transcriptase reaction (without SSII) was performed in parallel to ensure the absence of genomic DNA contamination. Real-time PCR was performed with $25 \mathrm{ng}$ of cDNA in a final volume of $20 \mu \mathrm{L}$ using the SYBR Green TaqMan Universal PCR master mix (Applied Biosystems, Courtaboeuf, France). Fluorescence was monitored and analyzed in a GeneAmp 7500 detection system instrument (Applied Biosystems). Analysis of $18 \mathrm{~S}$ ribosomal RNA was performed in parallel using the ribosomal RNA control TaqMan assay kit (Applied Biosystems) to normalize gene expression. 
TABLE 1. Primers Used for Real-time RT-PCR Experiments

\begin{tabular}{lll}
\hline & \multicolumn{1}{c}{ Sense } & Antisense \\
\hline $\begin{array}{l}\text { Mice } \\
\text { Adiponectin }\end{array}$ & TATAAGCGGCTTCTCCAGGCT \\
Leptin & TGGAATGACAGGAGCTGAAGG & TGGCTATCTGCAGCACATTTTG \\
HSL & GGGCTTCACCCCATTCTGA & CTGAAGGCTCTGAGTTGCTCAA \\
IL-6 & GGCTTACTGGGCACAGATACCT & CAAGAAGGCAACTGGATGGAA \\
MCP-1 & GCCCACCAAGAACGATAGTCA & CCAGCCTACTCATTGGGATCA \\
F4/80 & GCAGTTAACGCCCCACTCA & GCAGGCGAGGAAAAGATAGTGT \\
Human & TGACAACCAGACGGCTTGTG & TATAAGCGGCTTCTCCAGGCT \\
Adiponectin & & TGGCTATCTGCAGCACATTTTG \\
HSL & TGGAATGACAGGAGCTGAAGG & CTGAAGGCTCTGAGTTGCTCAA \\
\hline
\end{tabular}

Results are expressed as $2^{(\mathrm{Ct} 18 \mathrm{~S}}-\mathrm{Ctgene}^{2}\left[1-\left(1 / 2^{\text {(Ctgene }-}\right.\right.$ $\left.\mathrm{CtRT}_{-}\right)$] $, \times 100,000$, where $\mathrm{Ct}$ corresponds to the number of cycles needed to generate a fluorescent signal above a predefined threshold. All primers used (Table 1) were validated for PCR efficiency.

\section{Protein Expression by ELISA}

$\mathrm{CF}$ and MAT from mice with MDS >4 were collected. Samples were then processed for ELISA using commercial kits to determine levels of adiponectin and leptin (Invitrogen) according to the manufacturers' protocols and data are expressed as concentration per mg of protein.

\section{Western Blot}

Samples were homogenized on ice in an extraction buffer (24 mM Tris buffer, pH 7.4 containing $137 \mathrm{mM}$ $\mathrm{NaCl}, 2,68 \mathrm{mM} \mathrm{KCl}, 0,1 \%$ (w/v) SDS, $1 \%$ (v/v) Igepal, $0.5 \%(\mathrm{w} / \mathrm{v})$ sodium deoxycholate, supplemented with protease inhibitor cocktail $1 \mathrm{mM}$; Roche).

For analysis, $20 \mu \mathrm{g}$ of protein was loaded onto a $10 \%$ SDS-polyacrylamide gel and transferred to nitrocellulose membranes (Whatman Biosystems, UK) at $80 \mathrm{~V}$ for 1 hour. Nonspecific binding sites were blocked for 1 hour at room temperature in $24 \mathrm{mM}$ Tris-buffered saline $(\mathrm{pH} 7.4)$ containing $0.1 \%$ Tween 20 and $5 \%$ milk. Membranes were then incubated with rabbit anti-perilipin $1 / 400$ or rabbit anti-actin 1/1000 antibodies (Cell Signaling Technology, Danvers, MA) overnight at $4^{\circ} \mathrm{C}$. After washing, membranes were incubated with fluorescent CF770 antirabbit 1/10,000 antibody (Biotium, Hayward, CA) with gentle rocking and protected from light. Finally, they were scanned on an infrared imaging system Odyssey (Li-Cor, Lincoln, NE).

\section{Data Analysis}

Data are expressed as mean \pm SEM. For statistical analysis GraphPad Prism 4.0 (GraphPad, San Diego, CA) was used. Between-group comparison within groups was performed by Student's paired $t$-test. Multiple comparisons within groups were performed by repeated measures oneway analysis of variance (ANOVA) followed by Bonferroni's Multiple Comparison Test. Statistical significance was accepted at $P<0.05$.

\section{Ethical Considerations}

Animal care and work protocols were approved by the regional ethical committee of Midi-Pyrénées (Agreement \#MP/02/46/11/08). For human studies, all subjects provided written and informed consent to participate.

\section{RESULTS}

\section{Model of Colitis and Development of CF}

To set up an animal model allowing CF development, a protocol was established based on the DNBS model. Male Balb/c mice weighing $23 \mathrm{~g}$ were intrarectally instilled with a catheter at $4 \mathrm{~cm}$ from the anus with $100 \mu \mathrm{L}$ of a highly concentrated solution of DNBS: $260 \mathrm{mg} / \mathrm{kg}$ diluted in 50\% ethanol and sacrificed 3 days after instillation. Three days after instillation, during the peak of colonic inflammation, $20 \%$ mortality was observed and $40 \%$ of treated mice developed only a moderate inflammation, characterized by MDSs between 0 and 4. Moreover, $40 \%$ of mice developed a severe inflammation with $\mathrm{MDS}>4$ (Fig. 1a) reflected by large colonic ulcerative and necrosis areas. CF development was specifically observed in all mice with MDS $>4$, but not in animals with moderate colitis severity (MDS $\leq 4)$ (Fig. 1b). As observed in $\mathrm{CD}$ 
a

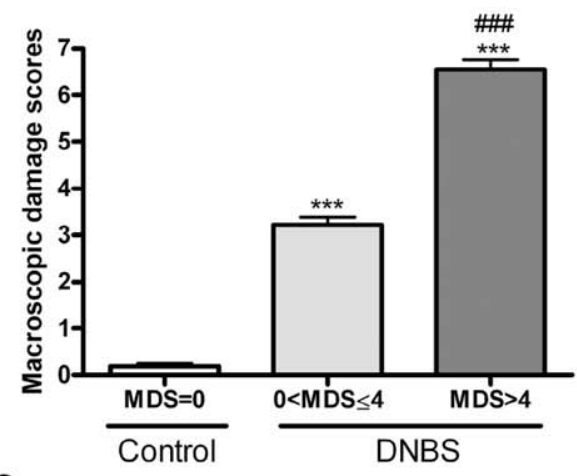

b

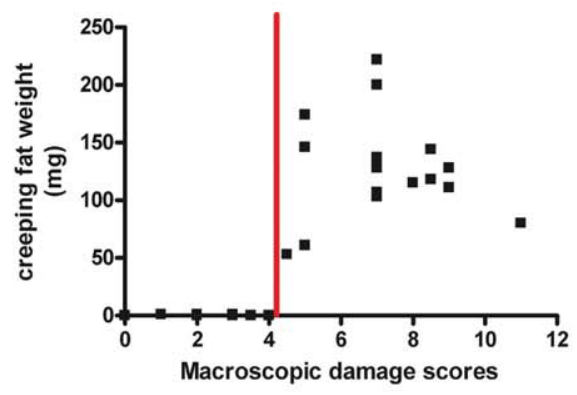

C
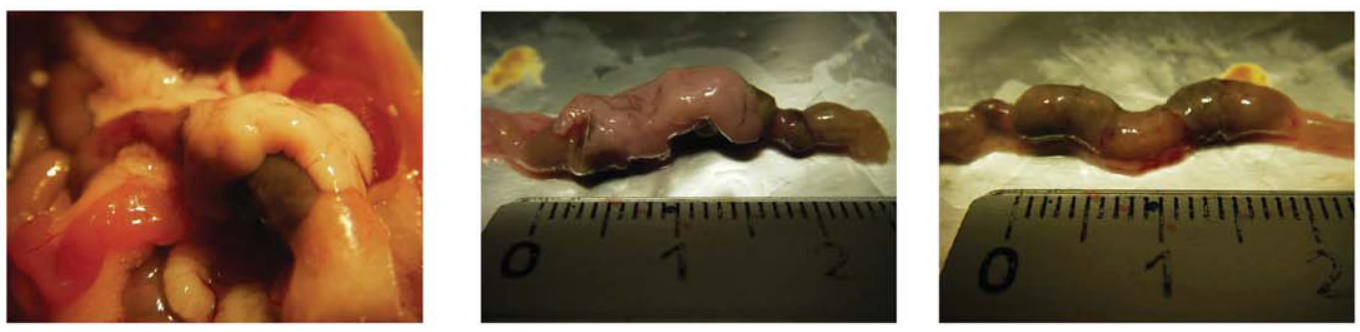

d

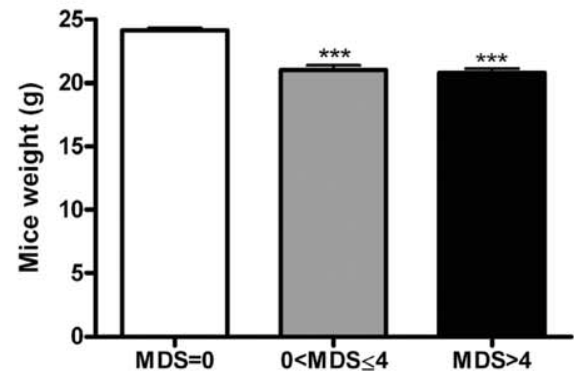

e
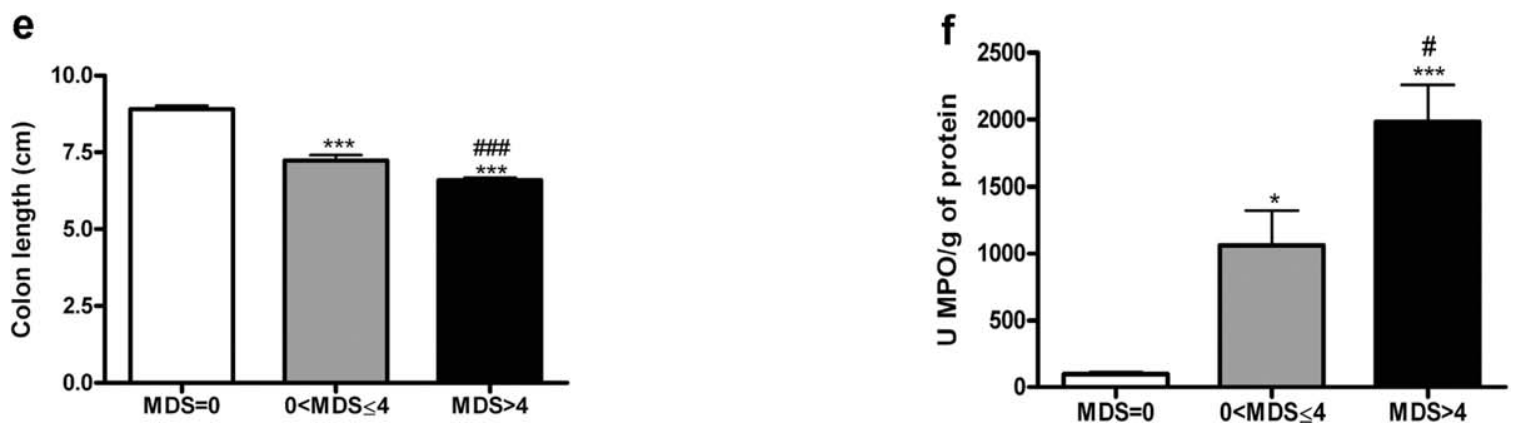

FIGURE 1. Creeping fat development according to severity of colitis and inflammation induced by DNBS. Mice were IR infused with $100 \mu \mathrm{L}$ of DNBS (50\% ethanol) and sacrificed 3 days later. Evaluation of MDS was used to classify mice in three groups according to severity of colitis: controls mice $(M D S=0)$ and DNBS mice with MDS less or more than four (MDS $\leq 4$ and MDS > 4) (a). CF developed only in mice with MDS $>4(b$, red line defines MDS $=4)$. In inflamed mice, $C F$ appeared a sleeve surrounding the ulcerated areas of colon (c). We evaluated the mice body weight (d), the length of colon (e), and we assayed colonic MPO activity (f). Data are expressed as means \pm SEM $(n=15)$, ${ }^{*} P<0.05,{ }^{* * *} P<0.001$ versus MDS $=0$ (control) and \#P<0.05, \#\#P $<0.001$ versus $0<\mathrm{MDS} \leq 4$ (moderate inflammation).

patients, ${ }^{5} \mathrm{CF}$ appears as a sleeve surrounding the ulcerated areas of the inflamed colon in mice (Fig. 1c). Macroscopic observations revealed a compact and fatty appearance of this tissue as observed in CD (Fig. 1c). Interestingly, 7 days after DNBS instillation, a remission of colitis was assessed by low MDS (1-4), and was characterized by the absence of CF (data not shown). DNBS-instilled mice also showed characteristic features of inflammation, such as a significant global body weight loss similarly described in $\mathrm{CD}^{1}$ (Fig. 1d). Moreover, in mice with $\mathrm{CF}$ (MDS >4), both a significant colon shortening and increase of colonic myeloperoxidase (MPO: a marker of neutrophil infiltration) 
a

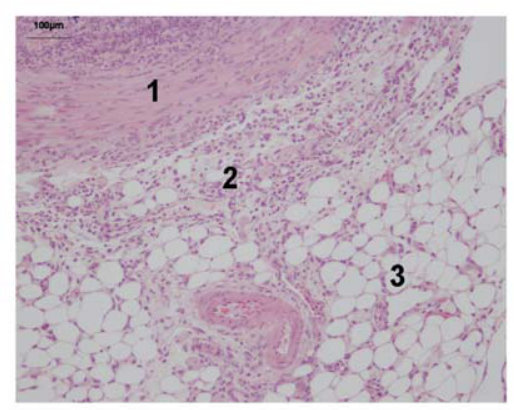

C

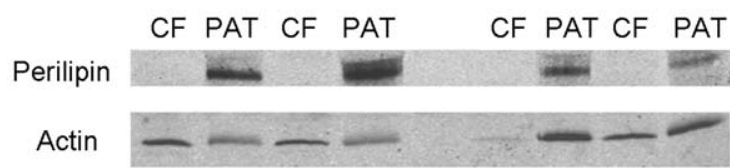

b

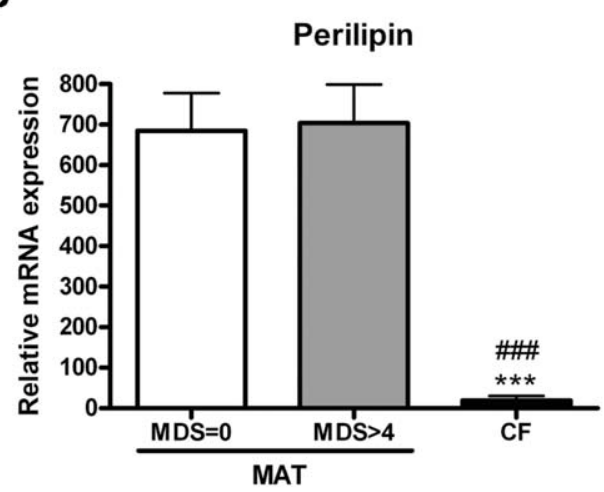

d

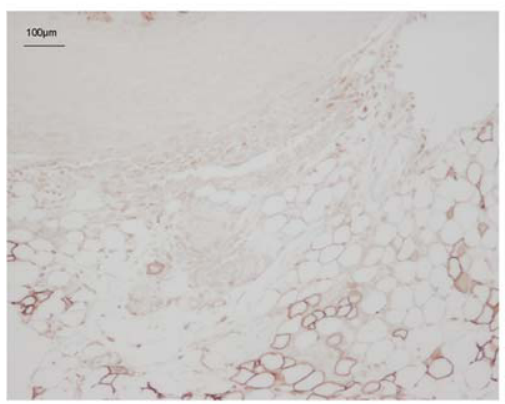

g

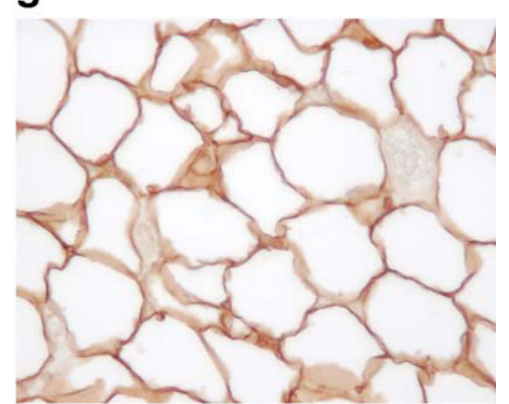

FIGURE 2. Study of perilipin in CF. H\&E staining was performed on paraffin slices of CF $(\times 10)$ and showed (1) fibroblastic area, (2) inflammatory area, and (3) adipose-like cells (a). Messenger RNA encoding perilipin (b) and HSL (e) were quantified by real-time RT-PCR in both MAT of mice with MDS $=0$ and MDS $>4(n=5)$ and in CF $(n=8)$. The perilipin protein expression in perigonadic adipose tissue (PAT) and CF was studied by Western blot $(n=6)(c)$. Immunohistochemistry for perilipin was performed $(\times 10)$ in the same slices used in $2 a(d)$ and in a perigonadic adipose tissue slide (e). A higher magnification $(\times 40)$ of $(d)$ and $(e)$ were performed (respectively, $f$ and $g)$.

activity compared to either control mice and mice with MDS $\leq 4$ were observed (Fig. 1e,f). Taken together, these data show that $\mathrm{CF}$ development was clearly correlated with the severity of colonic inflammation.

\section{Is CF an Adipose Tissue?}

$\mathrm{H} \& \mathrm{E}$ staining was performed in $\mathrm{CF}$ and revealed the presence of fibroblastic, inflammatory, and adipose-like cells (Fig. 2a). CF and MAT were digested by collagenase, allowing separation of two classical fractions: adipocytes and stroma vascular fraction (SVF). Adipocytes and SVF were obtained after MAT digestion (data not shown). Surprisingly, no adipocyte was recovered after CF digestion. Similarly, no staining by red oil O (a specific lipid dye) was observed in CF (data not shown). Moreover, the expression of mRNA and protein of perilipin, a lipid droplet-coating protein, were undetectable in CF (Fig. 2b,c) in comparison to MAT (Fig. 2b) and to perigonadic adipose tissue (Fig. 2c). These data were reinforced by a drastic decrease or the absence of perilipin immunoreactivity in CF (Fig. 2d), compared with perigonadic adipose tissue (Fig. 2e). Moreover, a higher magnification of the 
a

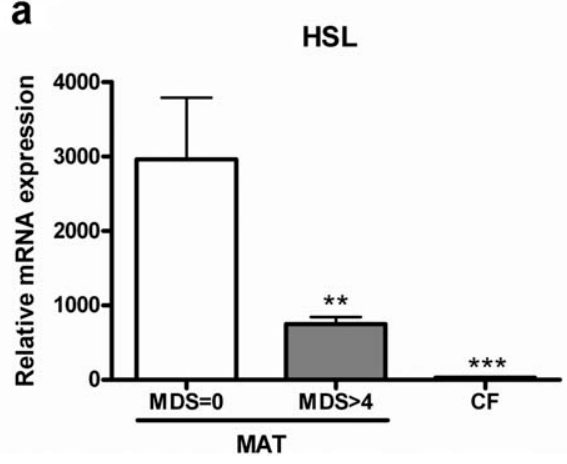

C

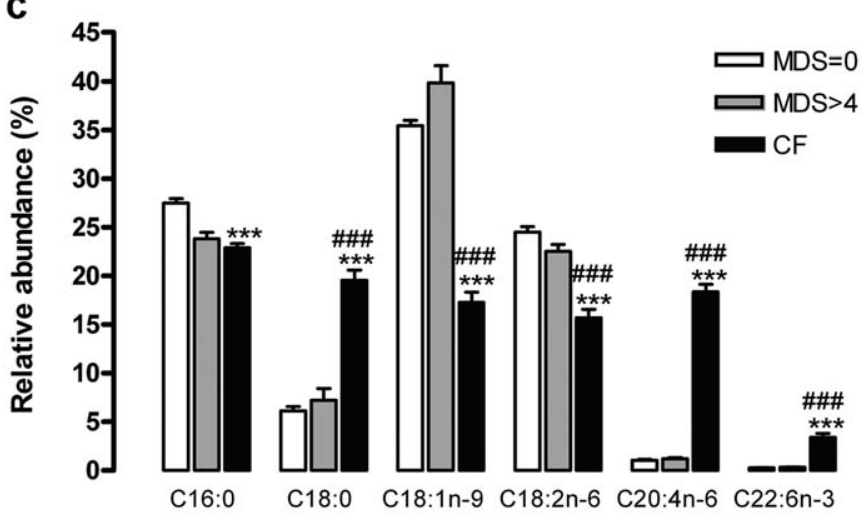

b

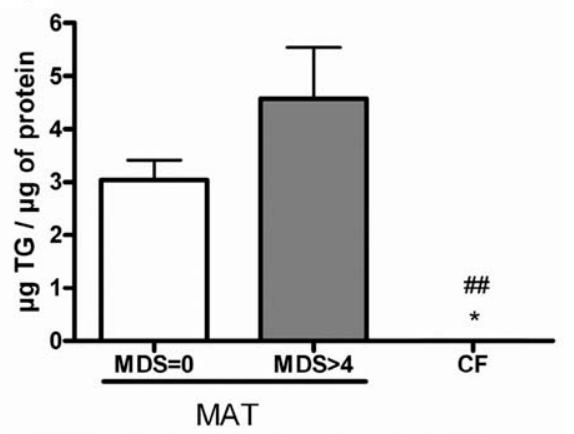

d

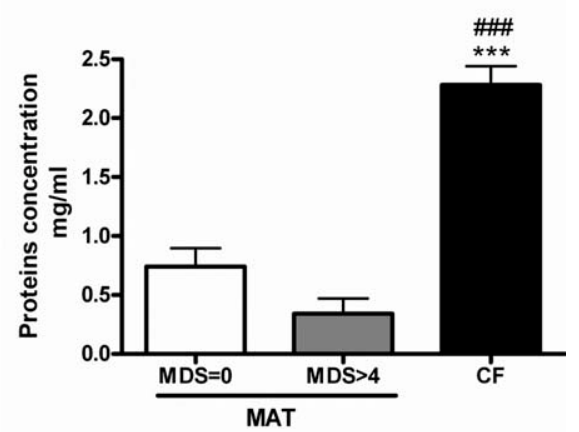

FIGURE 3. mRNA encoding HSL were quantified by real-time RT-PCR in both MAT of mice with MDS $=0$ and MDS $>4$ ( $n=$ 5) and CF $(n=8)$ (a). Triglycerides were assayed in control mice and DNBS mice with MDS $>4(n=4)(b)$. The nature of fatty acid that compose MAT $(n=5)$ and CF $(n=4)$ were studied (c). Protein assay was performed in MAT and CF ( $n=6)$

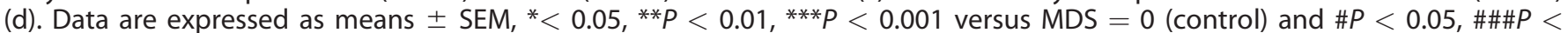
0.001 versus MDS $>4$ (moderate inflammation).

"adipose-like cells" from CF (Fig. 2f) revealed that these cells have a smaller size compared with adipocytes from perigonadic adipose tissue (Fig. 2g). Messenger RNA encoding hormone-sensitive lipase (HSL), an enzyme involved in lipolysis, was almost undetectable in comparison to MAT (Fig. 3a). Similarly, triglyceride (TG) levels were very low in CF (Fig. 3b), showing that CF does not store energy as TG. Consistent with this observation, the fatty acid (FA) composition of CF was found to be clearly different from that of MAT. As shown in Figure 3c, CF contained a higher proportion of FA predominantly found in membrane phospholipids (C18:0, C20:4n-6, C22:6n-3) rather than in TG such as $\mathrm{C} 18: 1 \mathrm{n}-9$ and $\mathrm{C} 18: 2 \mathrm{n}-6$ (Fig. $3 c)$. This observation could be related to the higher concentration of proteins found in CF compared to MAT (Fig. 3d). Both observations suggest a higher cellularity in CF.

In inflamed animals the expression of mRNA encoding leptin and adiponectin, two adipocytokines expressed by adipocytes, was significantly decreased in MAT and close to zero in CF (Fig. 4a,b). In the same way, the protein level of these two adipokines were significantly lower in MAT than in $\mathrm{CF}$, in mice with MDS $>4$ (Fig. 4c,d). Accordingly, plasma levels of adiponectin were decreased in DNBS-treated mice (Fig. 4e). MAT of both control and DNBS mice showed the same pattern of Pref-1 (preadipocyte factor-1) expression (Fig. 4f). By contrast, Pref-1 expression was markedly higher in CF (Fig. 4f), suggesting that $\mathrm{CF}$ cells include preadipocytes and/or fibroblasts but not mature adipocytes.

\section{CF: An Inflammatory Tissue}

Monocyte chemoattractant protein-1 (MCP-1) plays an important role in the recruitment of monocytes at sites of injury. Interestingly, we found MCP-1 expression significantly higher in inflammatory than in control conditions (Fig. 5a), both in MAT and CF. Moreover, MPO activity was significantly increased in MAT from CF-developing mice (MDS >4) in comparison with MAT from control mice. Further, the strongest MPO activity was observed in CF (Fig. 5b). In our model, as expected, the expression of mRNA encoding IL-6 in MAT and CF was higher under inflammatory than control conditions (Fig. 5c). In addition, plasma levels of IL-6 were also increased in DNBS-treated 
a
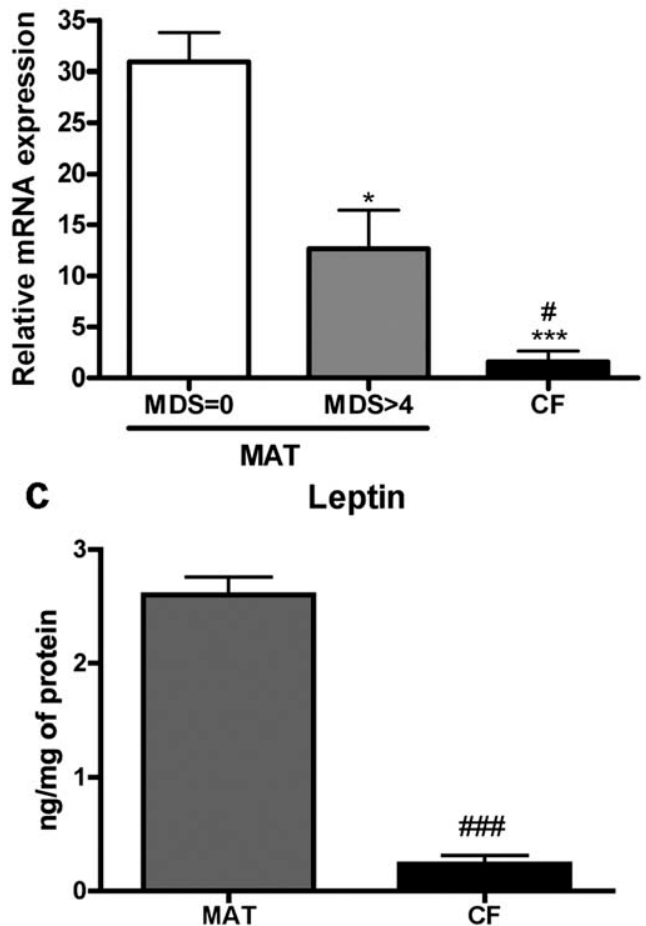

e

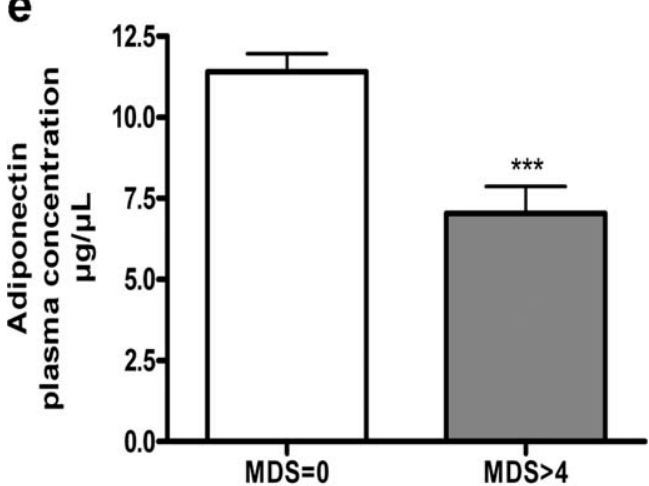

b
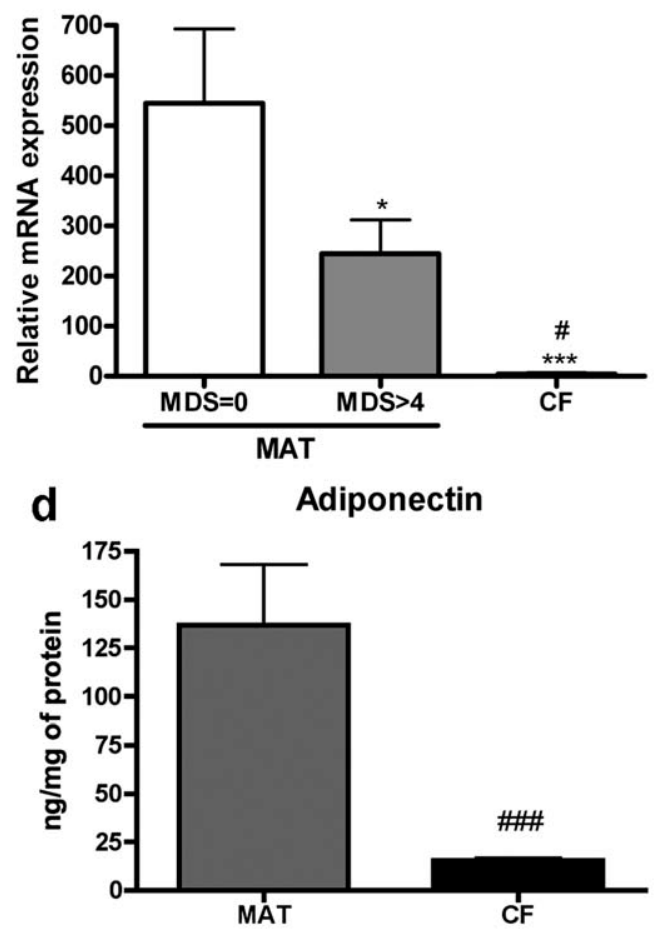

f

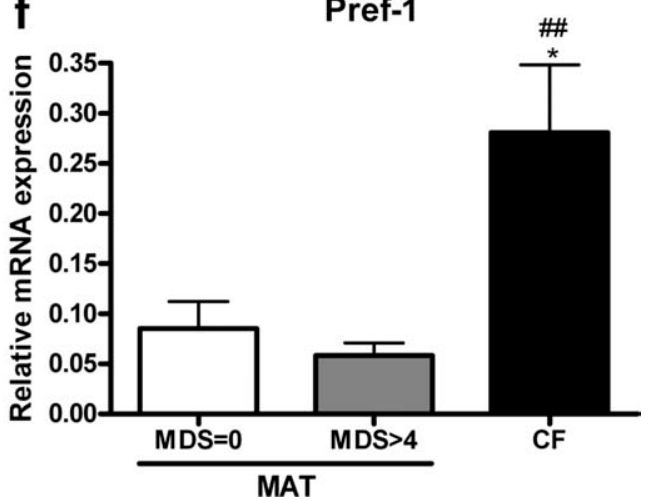

FIGURE 4. Expression of adipocytokines. mRNA encoding leptin (a), adiponectin (b), and Pref-1 (f) were quantified by realtime RT-PCR in both MAT of mice with MDS $=0$ and MDS $>4(n=5)$ and CF $(n=8)$. The protein level of leptin (c) and adiponectin (d), were quantified by ELISA in both MAT $(n=5)$ and CF $(n=8)$ of mice with MDS $>4$. The plasmatic levels of adiponectin (e) was evaluated by ELISA in MDS $=0$ and MDS $>4$ mice. Data are expressed as means \pm SEM, ${ }^{*}<0.05,{ }^{* *} P<$ 0.001 versus $M D S=0$ (control) and $\# P<0.05$ versus MDS $>4$ (moderate inflammation).

mice (Fig. 5d). Finally, the expression of F4/80, a widely used marker of tissue macrophages in mice, was significantly increased in CF compared to MAT of both control and inflamed mice (Fig. 5e).

\section{Human CF}

Metabolic marker (HSL) and adipokine (leptin, adiponectin) expression were analyzed in human $\mathrm{CF}$, MAT, and subcutaneous adipose tissue (SC) recovered from five $\mathrm{CD}$ patients. As expected, a depot-specific expression of adiponectin and leptin was observed, according to the tis- sue sample origin. Leptin expression was higher in SC in comparison to MAT. ${ }^{13}$ On the contrary, mRNA encoding adiponectin was strongly expressed in MAT compared with SC (Fig. 6). The level of all markers was weak in CF compared to MAT from CD patients (Fig. 6). Thus, the expression profile of these markers in human $\mathrm{CF}$ was similar to murine $\mathrm{CF}$.

\section{DISCUSSION}

Although $\mathrm{CF}$ has long been recognized in $\mathrm{CD}$ patients, ${ }^{3}$ our current knowledge of the nature and roles of 
a

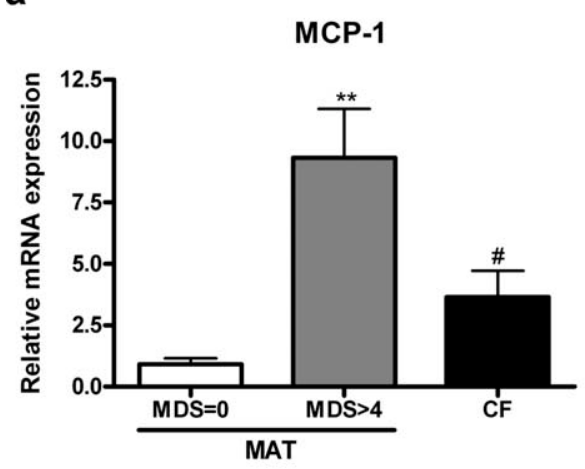

C

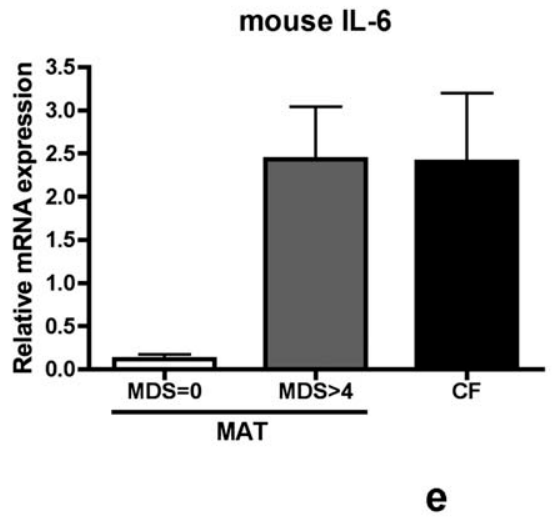

b

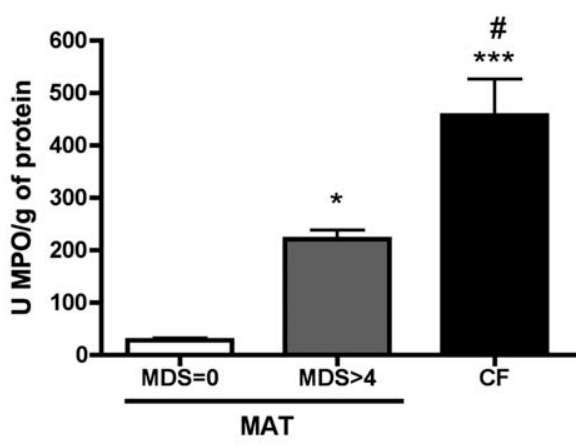

d

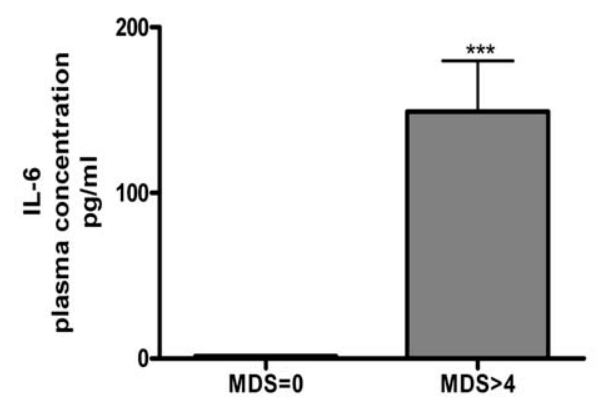

$\mathrm{F} 4 / 80$

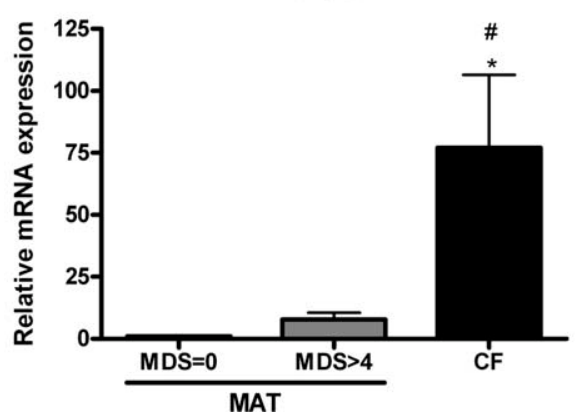

FIGURE 5. Study of inflammatory pattern. mRNA encoding MCP-1 (a), IL-6 (c), and F4/80 (e) were quantified by real-time PCR in both MAT of mice with MDS $=0$ and MDS $>4(n=5)$ and CF $(n=8)$. MPO activity was assayed in MAT of mice with MDS $=0$ and MDS $>4$ and in CF $(n=10)(b)$. The plasmatic level of IL-6 (d) was evaluated by ELISA in MDS $=0$ and MDS $>4$ mice. Data are expressed as means \pm SEM, ${ }^{*}<0.05,{ }^{* *} P<0.01,{ }^{* * *} P<0.001$ versus MDS $=0$ (control) and \#P<0.05 versus MDS >4 (moderate inflammation).

this ectopic tissue surrounding the necrotic areas is limited. We have standardized a protocol of DNBS-induced colonic inflammation to set up an animal model allowing CF development. We report that $\mathrm{CF}$ development is clearly correlated with the severity of colitis illustrated by elevated colonic MDS, MPO, and a loss in body weight in mice. Indeed, only mice with a severe inflammation (MDS >4) including large necrosis areas developed CF. In our experiments, this specific CF development was allowed by using a unique combination of parameters, never mentioned in the literature, regarding DNBS concentration $(260 \mathrm{mg} / \mathrm{kg}$ in $50 \% \mathrm{EtOH}$ ), mouse sex (male), strain (Balb/c), age (9 weeks), and weight ( $23 \mathrm{~g})$, allowing for the first time a model of mice CF to be described and studied. In humans, $\mathrm{CF}$ is commonly considered an extension of MAT. ${ }^{4}$ As far as we know, no study has characterized $\mathrm{CF}$ as a functional or metabolic active adipose tissue. While WAT is known as a tissue that stores energy in adipocytes as triglycerides 


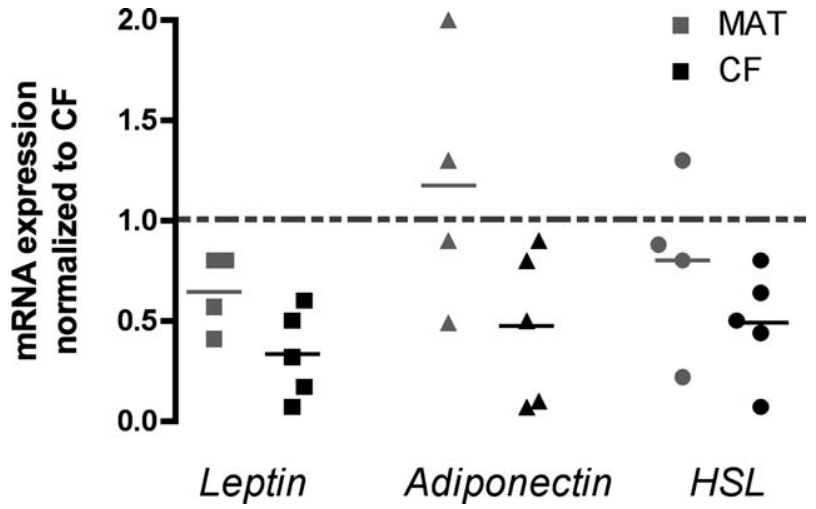

FIGURE 6. Study on human tissues. The expression of mRNA encoding leptin, adiponectin, and HSL in CF $(n=5)$ versus MAT $(n=4)$ and subcutaneous adipose tissue $(n=$ 5) were quantified in human samples by real-time RT-PCR. Expression levels in CF were normalized to the ones in subcutaneous adipose tissue, represented by the gray line.

(lipogenesis), and releases energy as free fatty acids (lipolysis), our results show that in mice, $\mathrm{CF}$ is characterized by the absence of adipocytes, no TG storage, and no lipolytic activity. We also showed that the expression of Pref- 1 is enhanced in CF. Pref-1 is described as undetectable in mature adipose cells, and used as a marker of preadipocytes, ${ }^{14}$ i.e., fibroblastic-like cells. Thus, CF cells might include preadipocytes and/or fibroblasts but not mature adipocytes. Consequently, CF cannot be described as a typical adipose tissue in our model.

In our model, a modification of MAT was also observed. Indeed, MAT from DNBS mice displays a loss of the adipose profile, assessed by a decrease of leptin, adiponectin, and HSL in comparison with MAT from control mice. These data are consistent with studies of Mattacks et al, ${ }^{15}$ which described a decrease of lipid markers in MAT in a model of TNBS-induced colitis. Moreover, the increase of inflammatory markers (IL-6, MCP-1, MPO) in MAT from DNBS mice, in comparison with MAT from control mice, allows defining this adipose tissue as an inflammatory tissue. These results are consistent with the literature. Indeed, as referred to by Karagiannidis et $\mathrm{al}^{16}$ in a close model of TNBS-induced colitis in rat, the induction of colitis causes an inflammatory response in MAT illustrated by an increase of IL- 6 and MCP-1 in this adipose tissue.

Concerning $\mathrm{CF}$, we have demonstrated that both mRNA expression and the protein level of adiponectin are lower in CF compared to MAT, in line with decreased plasma levels. These data are in accordance with studies performed in CD patients, ${ }^{17}$ while in mice, the pro- or antiinflammatory role of adiponectin remains controversial. ${ }^{18,19}$ In vitro, IL-6 has been shown to inhibit adiponectin expression and secretion. ${ }^{20}$ In our mice model, the expression of IL- 6 in $\mathrm{CF}$, and plasma level of IL-6, are increased. This suggests that the decreased adiponectin expression observed in our model may be a consequence of high IL-6 levels, giving CF a proinflammatory profile. In the same line, $\mathrm{CF}$ can be described as an inflammatory tissue infiltrated by neutrophils and macrophages. It is noteworthy that macrophages can present either tissue-destructive or repair activities. ${ }^{21}$ In the model of muscle damage, for instance, massive macrophage infiltration is observed at the site of injury and is involved in the muscle-healing processes. ${ }^{22}$ In the first step, necrosis of myocyte recruits proinflammatory macrophages (namely "M1") at the site of injury. These cells induce growth and proliferation of muscle cells. In the second step, M1 cells switch toward antiinflammatory macrophages ("M2") and lead to myogenic differentiation and myofiber growth. ${ }^{22}$ In our model, severe colitis induced by DNBS instillation can lead to a break of the colonic wall. Therefore, CF may play a double positive role: first a protective one against colonic perforation via a sleeve formation around the ulcerative colonic segment, preventing gut content leakage and possible endotoxinemia; and second a role in colonic wall healing via numerous macrophages present in $\mathrm{CF}$.

To establish the relevance of our mouse model, we analyzed metabolic marker (HSL) and adipokine (leptin and adiponectin) expression in MAT, CF, and subcutaneous adipose tissue (SC) human samples. We showed a weak expression of leptin, adiponectin, and HSL in CF compared with MAT. It is noteworthy that an increase of leptin and adiponectin in MAT from CD patients has been reported, ${ }^{8,23}$ but in these studies MAT from diverticulis or colon cancer patients was considered controls, while we used both MAT and SC adipose tissues recovered from the same patient as controls. Thus, $\mathrm{CF}$ recovered either from experimental colitis in mice or $\mathrm{CD}$ in humans appears to share the same expression pattern regarding the markers examined.

In conclusion, we established a description of $\mathrm{CF}$ as an inflammatory tissue, and for the first time not as an adipose tissue. Indeed, $\mathrm{CF}$ does express inflammatory markers (IL-6, MCP-1, F4/80) but not typical adipose tissue markers (perilipin, HSL, leptin, adiponectin) and does not store triglycerides. The setup of a novel animal model of colitis leading to $\mathrm{CF}$ development is another original contribution of this work. Besides the scientific novelty, these data offer the possibility to study and understand the role, function, and involvement of CF in CD physiopathology.

\section{ACKNOWLEDGMENTS}

The authors thank Sandra Grés, Estelle Wanecq, and Mathilde Levêque for technical assistance.

\section{REFERENCES}

1. Shamir R.Nutritional aspects in inflammatory bowel disease. J Pediatr Gastroenterol Nutr. 2009;48:S86-S88. 
2. Desreumaux P, Ernst O, Geboes K, et al. Inflammatory alterations in mesenteric adipose tissue in Crohn's disease. Gastroenterology. 1999;117:73-81.

3. Crohn BB, Ginzburg L, Oppenheimer GD.Regional ileitis; a pathologic and clinical entity. J Am Med Assoc. 1932;99:1323-1329.

4. Sheehan AL, Warren BF, Gear MW, et al. Fat-wrapping in Crohn's disease: pathological basis and relevance to surgical practice. $\mathrm{Br} J$ Surg. 1992;79:955-958.

5. Schaffler A, Herfarth H.Creeping fat in Crohn's disease: travelling in a creeper lane of research?Gut. 2005;54:742-744.

6. Borley NR, Mortensen NJ, Jewell DP, et al. The relationship between inflammatory and serosal connective tissue changes in ileal Crohn's disease: evidence for a possible causative link. J Pathol. 2000;190:196-202.

7. Karmiris K, Koutroubakis IE, Xidakis C, et al. Circulating levels of leptin, adiponectin, resistin, and ghrelin in inflammatory bowel disease. Inflamm Bowel Dis. 2006;12:100-105.

8. Barbier M, Vidal H, Desreumaux P, et al. Overexpression of leptin mRNA in mesenteric adipose tissue in inflammatory bowel diseases. Gastroenterol Clin Biol. 2003;27:987-991.

9. Wirtz S, Neufert C, Weigmann B, et al. Chemically induced mouse models of intestinal inflammation. Nat Protoc. 2007;2:541-546.

10. Wallace JL, Keenan CM, Cucala M, et al. Mechanisms underlying the protective effects of interleukin 1 in experimental nonsteroidal anti-inflammatory drug gastropathy. Gastroenterology. 1992;102:1176-1185.

11. Rebouissou S, Imbeaud S, Balabaud C, et al. HNF1 $\alpha$ inactivation promotes lipogenesis in human hepatocellular adenoma independently of SREBP-1 and carbohydrate-response element-binding protein (ChREBP) activation. J Biol Chem. 2007;282:14437-14446.

12. Bligh EG, Dyer WJ.A rapid method of total lipid extraction and purification. Can J Biochem Physiol. 1959;37:911-917.

13. Arner P.Regional differences in protein production by human adipose tissue. Biochem Soc Trans. 2001;29:72-75.
14. Sul HS, Smas C, Mei B, et al. Function of pref-1 as an inhibitor of adipocyte differentiation. Int J Obes Relat Metab Disord. 2000; 24(suppl 4):S15-19.

15. Mattacks CA, Sadler D, Pond CM.The cellular structure and lipid/protein composition of adipose tissue surrounding chronically stimulated lymph nodes in rats. J Anat. 2003;202:551-561.

16. Karagiannides I, Kokkotou E, Tansky M, et al. Induction of colitis causes inflammatory responses in fat depots: evidence for substance $\mathrm{P}$ pathways in human mesenteric preadipocytes. Proc Natl Acad Sci U S A. 2006;103:5207-5212.

17. Valentini L, Wirth EK, Schweizer U, et al. Circulating adipokines and the protective effects of hyperinsulinemia in inflammatory bowel disease. Nutrition. 2009;25:172-181.

18. Fayad R, Pini M, Sennello JA, et al. Adiponectin deficiency protects mice from chemically induced colonic inflammation. Gastroenterology. 2007;132:601-614.

19. Nishihara T, Matsuda M, Araki H, et al. Effect of adiponectin on murine colitis induced by dextran sulfate sodium. Gastroenterology. 2006;131:853-861.

20. Fasshauer M, Kralisch S, Klier M, et al. Adiponectin gene expression and secretion is inhibited by interleukin-6 in 3T3-L1 adipocytes. Biochem Biophys Res Commun. 2003;301:1045-1050.

21. Stout RD, Suttles J.Functional plasticity of macrophages: reversible adaptation to changing microenvironments. J Leukoc Biol. 2004;76: 509-513.

22. Arnold L, Henry A, Poron F, et al. Inflammatory monocytes recruited after skeletal muscle injury switch into antiinflammatory macrophages to support myogenesis. J Exp Med. 2007;204:1057-1069.

23. Yamamoto K, Kiyohara T, Murayama Y, et al. Production of adiponectin, an anti-inflammatory protein, in mesenteric adipose tissue in Crohn's disease. Gut. 2005;54:789-796. 